\title{
HE EFFECT OF THE DECREASE IN POWER INTENSITY OF SELF-OSCILLATING GRINDING IN A TUMBLING MILL WITH A REDUCTION IN AN INTRACHAMBER FILL
}

\author{
Deineka K. Yu. \\ Technical College of the National University of Water and \\ Environmental Engineering (TK of NUWEE), \\ Candidate of Technical Sciences (Ph.D), \\ Chairman of the Cycle Commission "Industry Engineering", Ukraine \\ Naumenko Yu. V. \\ National University of Water and Environmental Engineering \\ (NUWEE), Doctor of Technical Sciences (Dr.Sc), Associate \\ Professor, Professor of the Department of Construction, Road, \\ Reclamation, Agricultural Machines and Equipment, Ukraine
}

\begin{abstract}
Effect of the degree of chamber filling with the charge on efficiency of the selfoscillating grinding process in a tumbling mill has been assessed.

By using the approximate analytical and experimental method, dynamic effect of increasing the self-oscillating impact action of grinding fill on the crushed material was compared with the conventional steady-state motion mode. A significant increase in average sums of vertical components of the self-oscillating collision momenta and the average sums of power of such components with a decrease in the chamber filling degree was found. Manifestation of this effect is due to the increase in the self-oscillations swing with decreasing filling.

Technological effect of significant decrease in the specific power intensity and productivity growth of the innovative self-oscillating grinding process as compared to the characteristics of the conventional steady-state process with a reduction in the chamber filling degree have been experimentally established.

The effects established in operation have allowed us to predict rational parameters of the self-oscillating grinding process carried out in a tumbling mill with variation in the chamber filling degree

Keywords: tumbling mill, chamber filling degree, fill self-oscillation, specific power intensity in grinding

\section{Introduction}

Due to a series of their operational advantages, the tumbling type mills remain to be the main equipment in many industries for small-
\end{abstract}


and large-tonnage fine grinding of solid materials.

Replacement of the conventional steady-state grinding process with a novel self-oscillating process improves existing equipment of relatively low power efficiency [1,2]. Use of the phenomenon of excitation of self-oscillations makes it possible to apply conventional solutions to designing the tumbling mills with a smooth working chamber surface without additional activating elevators in a form of protruding elements which undergo rapid abrasive wear.

On the other hand, significant variability of the self-excited pulsation behavior of the rotating chamber fill depending on structural, kinematic, and technological parameters of equipment operation [3-7] makes it difficult to establish rational conditions for effective realization of the self-oscillating grinding process.

The data obtained from numerical simulation and experiments have shown a significant influence of the chamber filling degree $\kappa$ on parameters of the grinding process occurring in the tumbling mills. This effect consists in a growth of the impact action of the grinding fill with a decrease in $\kappa$. Instead, with an increase in $\kappa$, impact action is reduced and the abrasion effect increases, dissipation of kinetic energy of the grinding bodies increases because of collision and the grinding power efficiency is reduced. However, these results relate just to a conventional grinding process at simple conditions of steadystate intrachamber fill motion.

No models have been constructed to date to determine effect of the chamber filling degree $\kappa$ on grinding parameters in self-excitation of a complex mode of transient motion of the pulsating fill. Absence of such models is particularly negative in the case of realization of the innovative self-oscillating grinding process in tumbling mills.

In view of the above, the problem of predicting the effect of the degree of filling the chamber with the fill on dynamic force of the grinding bodies applied to the particles of the crushed material as well as on the technological and power efficiency of the process of selfoscillating grinding in the tumbling mill seems rather relevant.

\section{The aim and objectives of the study}

The study objective consists in establishing the effect of chamber filling degree on characteristics of dynamic action of the fill and technological and power parameters of conventional steady-state and 
innovative self-oscillating processes of grinding in a tumbling mill. It would make it possible to predict efficiency of realization of selfoscillating grinding processes at a varying degree of filling the chamber with fill.

To achieve this objective, the following tasks were set: to perform analytical and experimental modeling of dynamic action of the fill; to perform experimental modeling of technological and power parameters of the grinding processes in a tumbling mill.

\section{The process of grinding in a tumbling mill}

It is convenient to use dimensionless criterial parameters for modelling the grinding process in a tumbling mill. The drum rotation is defined by relative velocity $\psi_{\omega}=\omega \sqrt{R / g}$ where $\omega$ is the angular velocity of rotation; $R$ is the radius of the drum chamber; $g$ is gravitational acceleration.

Useful filling of the drum is defined by the degree of filling the chamber with the fill $\kappa=w /\left(\pi R^{2} L\right)$ where $w$ is the volume of the charge at rest; $L$ is the length of the drum chamber.

Conventional steady-state grinding process in a tumbling mill is realized at a moderate relative rotational velocity $\psi_{\omega}=0.7-0.9$. At the chamber filling degree $\kappa=0.25-0.45$, the fill circulates in a three-phase mode with formation of three flow zones in the chamber cross-section (Fig. 1).
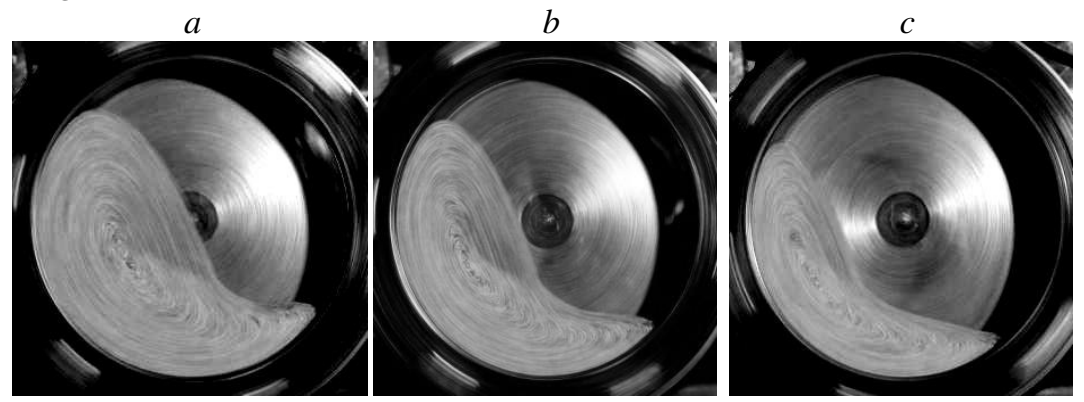

Fig. 1. A pattern of steady-state fill motion with absolute $d$ and relative $d /(2 R)=0.01$ 0.03 particle size, $\psi_{\omega}=0.75: \mathrm{a}-\kappa=0.45 ; \mathrm{b}-\kappa=0.35 ; \mathrm{c}-\kappa=0.25$

Conventionally, grinding (Fig. 2) is performed mainly by an impact action on the boundary BC of transition from the zone of restricted fall 2 to the zone of the creeping layer 3 and the abrasion 
action in the creeping layer 3. Technological results of grinding resulting from such actions are commensurate.

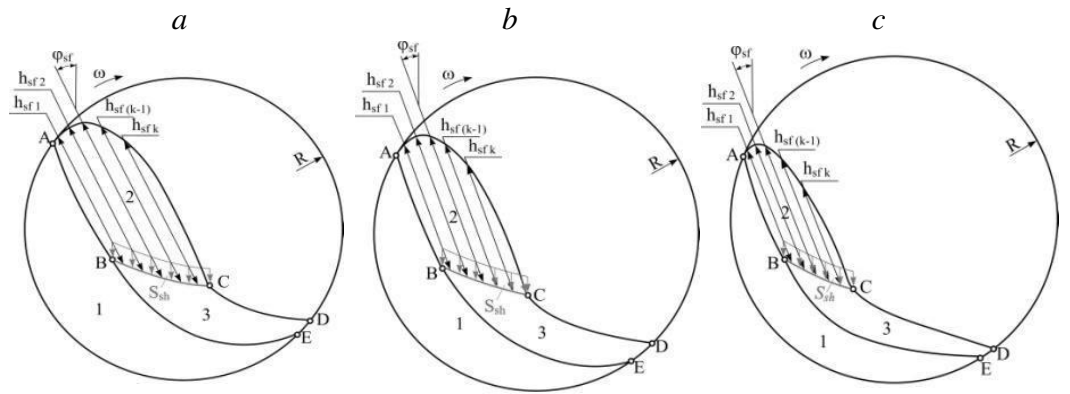

Fig. 2. Design diagram for determining the fill impact in a steady motion at $d /(2 R)=0.01-0.03$ and $\psi_{\omega}=0.75$ (according to Fig. 1$)$ ( 1 - solid state zone; 2 restricted fall zone; 3 - creeping zone): $\mathrm{a}-\kappa=0.45 ; \mathrm{b}-\kappa=0.35 ; \mathrm{c}-\kappa=0.25$

The innovative self-oscillating grinding process in a tumbling mill is realized in the case of increased rotational velocity $\psi_{\omega} \approx 1-1.2$. At $\kappa=0.25-0.45$, a pulsating zone of oscillating fill flow appears due to self-excitation. The creeping layer and the restricted fall zone partially (Fig. 3 and 4) or completely (Fig. 5) transform into this zone.

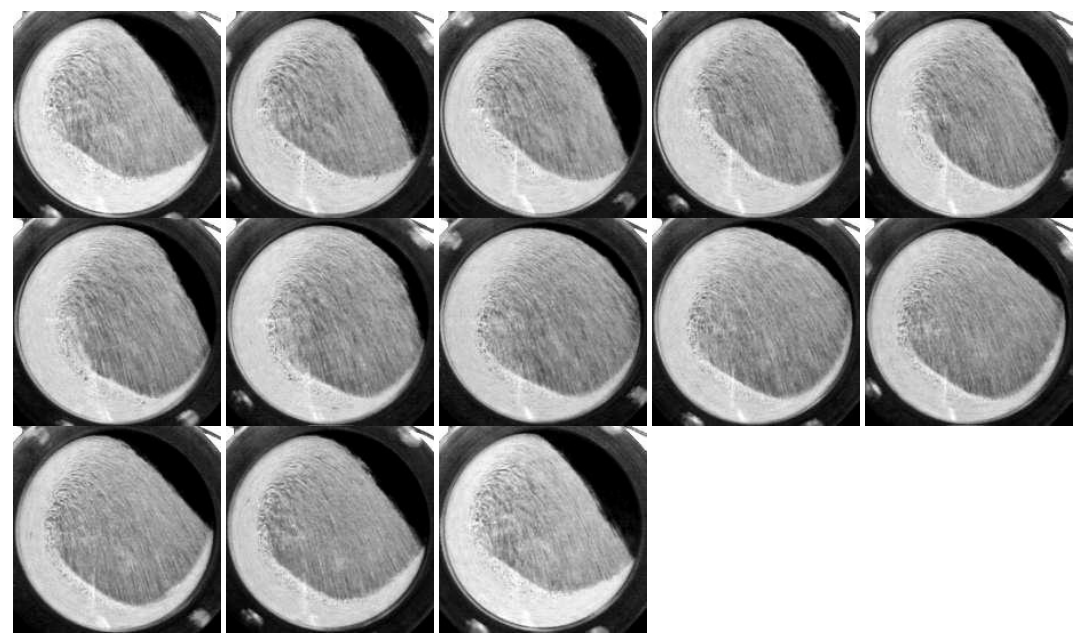

Fig. 3. Consecutive patterns of the fill motion over time for one period of selfoscillations with a maximum swing at $d /(2 R)=0.01-0.03, \kappa=0.45$ and $\psi_{\omega}=1.1$ 


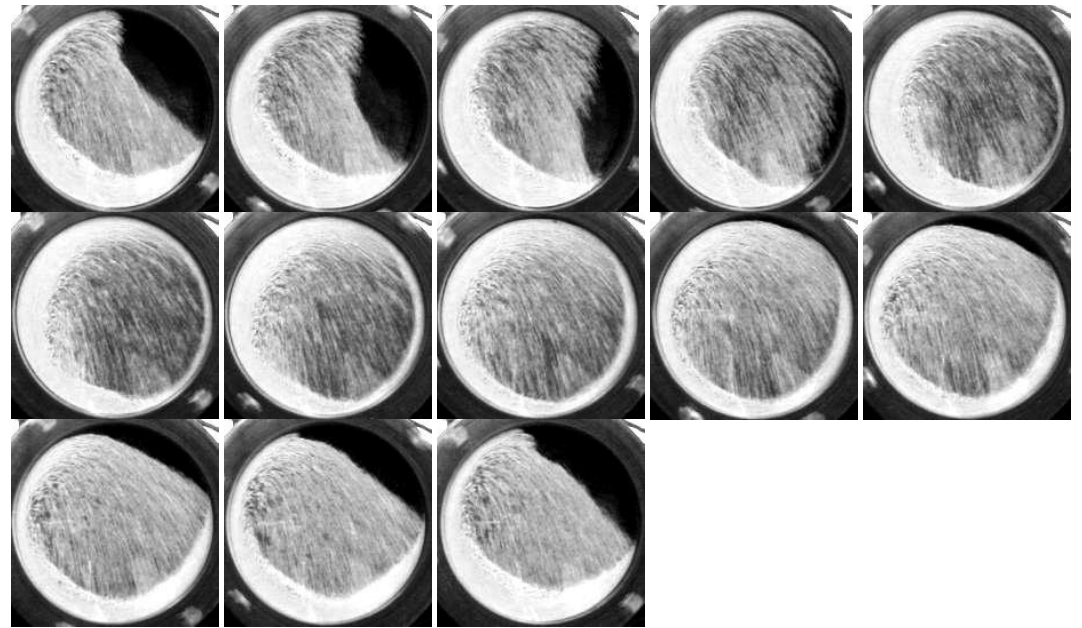

Fig. 4. Consecutive patterns of the fill motion over time for one period of selfoscillations with a maximum swing at $d /(2 R)=0.01-0.03, \kappa=0.35$ and $\psi_{\omega}=1.075$

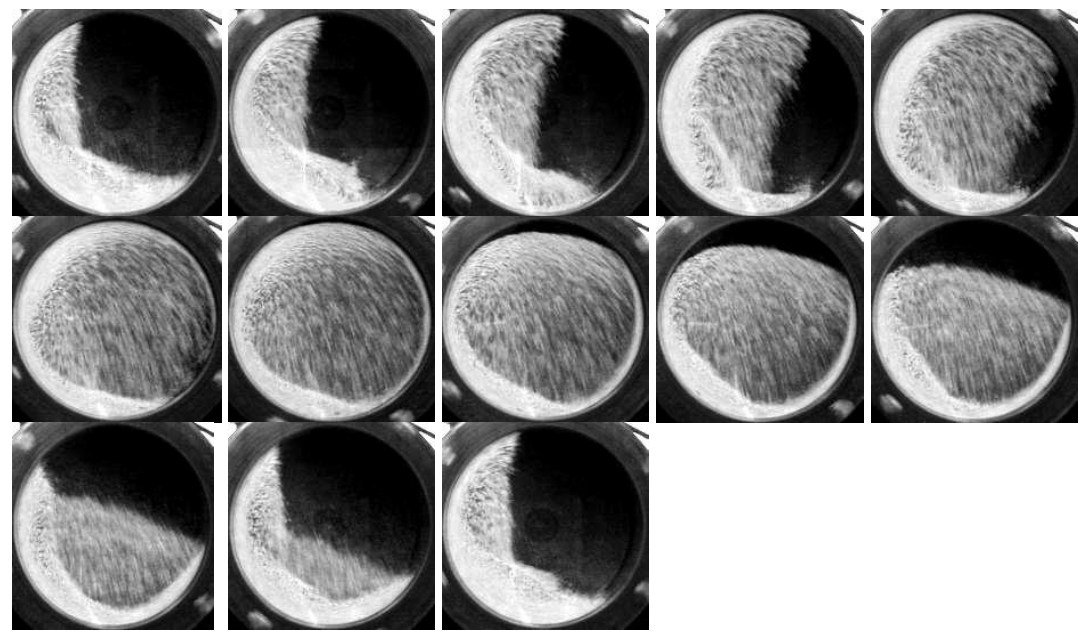

Fig. 5. Consecutive patterns of the fill motion over time for one period of selfoscillations with a maximum swing at $d /(2 R)=0.01-0.03, \kappa=0.25$ and $\psi_{\omega}=1.05$

The self-oscillating grinding (Fig. 6) is realized by an impact action on the BCE boundary including sections BC and CE. The BC boundary corresponds to the transition of the restricted fall zone 2 (Fig. $6 \mathrm{a}$ and $6 \mathrm{~b}$ ) or the pulsation zone 4 (Fig. 6c) to the solid state 
zone 1 . The CE section corresponds to the contact of the pulsation zone 4 with the chamber surface.
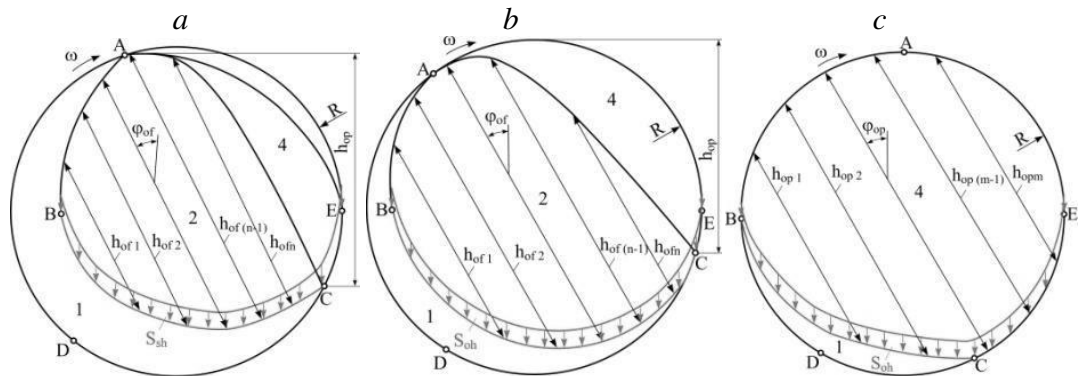

Fig. 6. Calculation diagram for determining impact of the fill in a self-oscillating motion at $d /(2 R)=0.01-0.03$ and $\psi_{\omega}=1.075$ (according to Fig. 3-5) $(1-$ solid state zone; 2 - restricted fall zone; 4 - pulsation zone): $\mathrm{a}-\kappa=0.45 ; \mathrm{b}-\kappa=0.35 ; \mathrm{c}-\kappa=0.25$;

The adopted qualitative model of fill behavior (Fig. 1-6) makes it possible to perform quantitative analysis of dynamic action for various chamber filling degrees $\kappa$.

\section{Analytical modeling of impact action of the fill}

It is convenient to estimate technological results of the grinding process at conventional and self-oscillatory modes of a mill by performing a comparative analysis of parameters for the filling's impact action only.

When a grinding particle $M_{v}$ hits the respective surface of the transition between zones of the filling's flow, there occurs a jump-like ultimate change in its speed over a small time $\tau$. In this case, the contact's surface is exposed to impact force $\bar{F}_{v}$. A measure for the impact interaction is the impact pulse $\bar{S}_{v}=\int_{1}^{\tau} \bar{F}_{v} d t$.

Duration of the impact is very low $\left(\tau \approx 10^{-2} \ldots 10^{-4} \mathrm{~s}\right)$. Since the impact pulse $S_{v}$ has a finite value, the impact force module of the milling body could be quite large $\left(F_{v} \rightarrow \infty\right.$ at $\left.\tau \rightarrow 0\right)$, which ensures the implementation of grinding process via the impact action. In this case, effect of the non-impact forces can be disregarded. 
It is expedient to estimate the technological effect of impact action not based on a value for the impact force, but rather based on its pulse, work, and power.

An impact pulse corresponds to a change in the amount of motion $\Delta \bar{Q}_{v}$ by a particle of mass $m_{v}$ over the time of impact

$$
\bar{S}_{v}=\Delta \bar{Q}_{v}=m_{v}\left(\bar{u}_{v}-\bar{v}_{v}\right),
$$

where $\bar{v}_{v}$ is the speed of a particle before the impact, $\bar{u}_{v}$ is the speed of a particle after the impact.

Work of the impact force corresponds to a change in the kinetic energy $\Delta T_{v}$ of a particle during impact

$$
A_{v}=\Delta T_{v}=m_{v}\left(\bar{u}_{v}-\bar{v}_{v}\right)^{2} / 2 \text {. }
$$

The largest, in terms of magnitude, and defining, in terms of effectiveness of the implementation of an operating process, component of the impact action is vertical. The impact under consideration is a complex non-perfect interaction between particles. Then the expressions for the vertical component of the impact pulse and work of the vertical component of the impact force, according to (1) and (2), can be approximately represented in the form

$$
\begin{gathered}
S_{v h}=m_{v} K_{v h v} v_{h v}, \\
A_{v h}=\left(m_{v} K_{v h v}^{2} v_{h v}^{2}\right) / 2,
\end{gathered}
$$

where $v_{h v}$ is the vertical component of particle's velocity $\bar{v}_{v}$ before the impact, $K_{v h v}=0-1$ is the coefficient of loss of the vertical component $v_{h v}$ of velocity $\bar{v}_{v}$ during impact.

Assuming

$$
v_{h v}=\sqrt{2 g h_{v}},
$$

expressions (3) and (4) take the form

$$
\begin{gathered}
S_{v h}=\sqrt{2 g} m_{v} K_{v h v} \sqrt{h_{v}}, \\
A_{v h}=g m_{v} K_{v h v}^{2} h_{v},
\end{gathered}
$$

where $h_{v}$ is the height of particle's fall before the impact, $g$ is the gravitational acceleration.

We shall further consider the vertical component of the impact action of particles at the surface of transition between zones of the filling's motion for $N(v=1.2, \ldots, N)$ grinding particles over an arbitrary time span $\Delta t$. Then, according to (5) and (6), expressions for the sum 
of vertical components of the impact pulses and the sum of work of the vertical components of impact forces over $\Delta t$ take the following form

$$
\begin{gathered}
S_{h}^{\Delta t}=\sqrt{2 g} \sum_{v=1}^{N} m_{v} K_{v h v} \sqrt{h_{v}}, \\
A_{h}^{\Delta t}=g \sum_{v=1}^{N} m_{v} K_{v h v}^{2} h_{v},
\end{gathered}
$$

The mean, over time $\Delta t$, value for the total power of the vertical components of impact forces corresponds to the average value for the sum of work of such forces $A_{h}^{u t}$ per unit time (1 s) and is equal to

$$
P_{h}=A_{h}^{u t}=A_{h}^{\Delta t} / \Delta t \text {. }
$$

For the case of the conventional steady mode of operation (Fig. 3), the sum of the vertical components of impact pulses over $\Delta t$ (7) can be calculated from formula

$$
S_{s h}^{\Delta t}=\sqrt{2 g} m_{s}^{\Delta t} K_{v h s} \sqrt{h_{s f}},
$$

where $m_{s}^{\Delta t}=\sum_{v=1}^{N} m_{v s}$ is the sum of masses of $N$ particles, $K_{v h s}$ is the average coefficient of loss of the vertical component of particles' velocity in a non-free fall zone, which can be determined using a method of the filling's flow visualization, $h_{s f}=\cos \varphi_{s f} \sum_{i=1}^{k} \frac{h_{s f i}}{k}$ is the average height of fall of $N$ particles in a non-free fall zone, $h_{s f i}$ is the elementary linearized trajectory of fall of a separate particle in a nonfree fall zone, $\varphi_{s f}$ is the angle of inclination to vertical of the averaged linearized trajectories of falling particles in a non-free fall zone.

The sum of the vertical components of impact pulses under a steady mode (10) for a single rotation of the drum is

$$
S_{s h}^{t n}=\sqrt{2 g} m_{s}^{t n} K_{v h s} \sqrt{h_{s f}},
$$

where $m_{s}^{t n}=m K_{t s}$ is the sum of masses of grinding particles that execute an impact within a single turn of the drum; $m=\pi R^{2} L \kappa \rho$ is the mass of the milling fill; $R$ is the radius of the drum's chamber; $L$ is the length of the drum's chambers; $\kappa$ is the degree of filling the chamber 
with a fill; $\rho$ is the density of the milling fill at rest; $K_{t s}$ is the loading's turnover under a steady mode.

Turnover describes the number of periods of circulation of the fill over a single drum rotation

$$
K_{t}=(2 \pi) /\left(t_{c} \omega\right),
$$

where $t_{c}$ is the duration of circulation period of a fill in the rotating drum's chamber, $\omega$ is the angular speed of the drum. Turnover can be determined based on an experimental analysis of the fill flow patterns.

The mean, over a single rotation of the drum, value for the sum of the vertical components of impact pulses under a steady mode per unit time is

$$
S_{s h}^{u t}=S_{s h}^{t n} / T_{s},
$$

where $T_{s}=2 \pi / \psi_{\omega s} \sqrt{R / g}$ is the period of drum rotation under a steady mode, $\psi_{\omega s}=\omega_{s} \sqrt{R / g}$ is the relative rotation speed of the drum under a steady mode, $\omega_{s}$ is the angular velocity of the drum under a steady mode. Then, taking into consideration (11) and (12),

$$
S_{s h}^{u t}=\left(g m K_{t s} \psi_{\omega s} K_{v h s} \sqrt{h_{s f} / R}\right) /(\sqrt{2} \pi) .
$$

For the case of the self-oscillatory mode of operation (Fig. 4), the sum of the vertical components of impact pulses over $\Delta t$ (7) can be approximately calculated from expression

$$
S_{o h}^{\Delta t}=S_{o f h}^{\Delta t}+S_{o p h}^{\Delta t}=\sqrt{2 g}\left(m_{o f}^{\Delta t} K_{v h o f} \sqrt{h_{o f}}+m_{o p}^{\Delta t} K_{v h o p} \sqrt{h_{o p}}\right),
$$

where $S_{\text {ofh }}^{\Delta t}$ is the sum of the vertical components of impact pulses of particles in a non-free fall zone over $\Delta t ; S_{o p h}^{\Delta t}$ is the sum of the vertical components of impact pulses of particles in a pulsating zone over $\Delta t ; m_{o f}^{\Delta t}=\sum_{v=1}^{N_{f}} m_{v o}$ is the sum of masses of $N_{f}$ particles in a non-free fall zone, which execute an impact over $\Delta t ; m_{o p}^{\Delta t}=\sum_{v=1}^{N_{p}} m_{v o}$ is the sum of masses of $N_{p}$ particles in a pulsating zone, which execute an impact over $\Delta t ; K_{v h o f}$ is the average coefficient of loss of the vertical component of velocity by particles in a non-free fall zone; $K_{v h o p}$ is the aver- 
age coefficient of loss of the vertical component of velocity by particles in a pulsating zone, $h_{o f}=\cos \varphi_{o f} \sum_{i=1}^{n} \frac{h_{o f i}}{n}$ is the average height of fall of particles in a non-free fall zone, $h_{o f i}$ is the elementary linearized trajectory of fall by a separate particle in a non-free fall zone, $\varphi_{o f}$ is the angle of inclination to vertical of the averaged linearized trajectories of falling particles in a non-free fall zone, $h_{o p}$ is the average height of fall by particles in a pulsating zone.

The sum of the vertical components of impact pulses under a selfoscillatory mode (14) for a single drum rotation is

$$
S_{o h}^{t n}=\sqrt{2 g}\left(m_{o f}^{t n} K_{v h o f} \sqrt{h_{o f}}+m_{o p}^{t n} K_{v h o p} \sqrt{h_{o p}}\right),
$$

where $m_{o f}^{t n}=m\left(1-\kappa_{o p}\right) K_{t o}$ is the sum of masses of particles in a nonfree fall zone, which execute an impact within a single drum rotation; $m_{o p}^{t n}=\left(m \kappa_{o p} \psi_{\omega o p}\right) / \psi_{\omega o}$ is the sum of masses of particles in a pulsating zone, which execute an impact within a single drum rotation; $K_{t o}$ is the turnover of fill under a self-oscillatory mode (Fig. 5); $\kappa_{o p}$ is the mass fraction of the pulsating zone in the mass of the entire fill; $\psi_{\omega o}=\omega_{o} \sqrt{R / g}$ is the relative speed of rotation of the drum in selfoscillatory mode; $\omega_{o}$ is the angular velocity of drum under a selfoscillatory mode; $\psi_{\omega o p}=2 \pi \sqrt{R / g} f_{o p}$ is the relative circular frequency of the filling self-oscillations; $f_{o p}$ is the cyclic frequency of selfoscillations.

Parameters for self-oscillations can be determined experimentally using a method for the visualization of a filling's flow. The mass share of pulsating zone $\kappa_{o p}$ is calculated based on an analysis of flow patterns. The cyclic frequency of self-oscillations $f_{o p}$ is established from an analysis of transient flow modes. The absolute mass and the mass share of a non-free fall zone and a pulsating zone are variable parameters over the period of self-oscillations: $m_{o f}^{t n}=v a r$, $m_{o p}^{t h}=v a r$ and $\kappa_{o p}=$ var. 
The mean, over a single drum rotation, value for the sum of the vertical components of impact pulses under a self-oscillatory mode per unit time is

$$
S_{o h}^{u t}=S_{o h}^{t n} / T_{o},
$$

where $T_{o}=2 \pi / \psi_{\omega o} \sqrt{R / g}$ is the period of drum rotation under a selfoscillatory mode. Then, taking into consideration (15) and (16)

$$
S_{o h}^{u t}=\frac{1}{\sqrt{2} \pi} g m\left[K_{t o}\left(1-\kappa_{o p}\right) \psi_{\omega o} K_{v h o f} \sqrt{\frac{h_{o f}}{R}}+\kappa_{o p} \psi_{\omega o p} K_{v h o p} \sqrt{\frac{h_{o p}}{R}}\right] .
$$

The average sum of the vertical components of impact pulses (17) over a period of self-oscillations varies from a minimum value when $\kappa_{o p}=0$

$$
S_{\text {ohmin }}^{u t}=\left(g m K_{t o} \psi_{\omega o} K_{\text {vhof }} \sqrt{h_{o f} / R}\right) /(\sqrt{2} \pi),
$$

to a maximal value when $\kappa_{o p}=\kappa_{o p m a x}$

$$
S_{\text {ohmal }}^{u t}=\frac{1}{\sqrt{2} \pi} g m\left[K_{t o}\left(1-\kappa_{\text {opmax }}\right) \psi_{\omega o} K_{\text {vhof }} \sqrt{\frac{h_{o f}}{R}}+\kappa_{o p m a x} \psi_{\omega o p} K_{v h o p} \sqrt{\frac{h_{o p}}{R}}\right] .
$$

Expressions for the mean value of total power of the vertical components of the impact forces of fill can be derived by analogy to the above procedures for the formalization of average sums of the vertical components of impact pulses.

An expression for the total work of the vertical components of impact forces for a single drum rotation under a steady mode, taking into consideration (7), (8) and (11), takes the form

$$
A_{s h}^{t n}=g m_{s}^{t n} K_{v h s}^{2} h_{s f} .
$$

The average total power of the vertical components of impact forces, taking into consideration (9), (12), (13) and (20), is

$$
P_{s h}=\left(g m K_{t s} \psi_{\omega s} \sqrt{g / R} K_{v h s}^{2} h_{s f}\right) /(2 \pi) .
$$

An expression for the total work of the vertical components of impact forces for a single drum rotation under a self-oscillatory mode, taking into consideration (7), (8) and (15), takes the form

$$
A_{o h}^{t n}=g\left(m_{o f}^{t n} K_{v h o f}^{2} h_{o f}+m_{o p}^{t n} K_{v h o p}^{2} h_{o p}\right) .
$$


The average total power of the vertical components of impact forces under a self-oscillatory mode, considering (9), (16), (17) and (22), is

$$
P_{o h}=g m \sqrt{g / R}\left[K_{t o}\left(1-\kappa_{o p}\right) \psi_{\omega 0} K_{\text {vhof }}^{2} h_{o f}+\kappa_{o p} \psi_{\omega o p} K_{\text {vhop }}^{2} h_{o p}\right] / 2 \pi .
$$

The average sum of power (23) over a period of self-oscillations changes, similar to (18) and (19), from a minimum

$$
P_{\text {ohmin }}=\left(g m \sqrt{g / R} K_{t o} \psi_{\omega o} K_{\text {vhof }}^{2} h_{o f}\right) /(2 \pi),
$$

to a maximal value

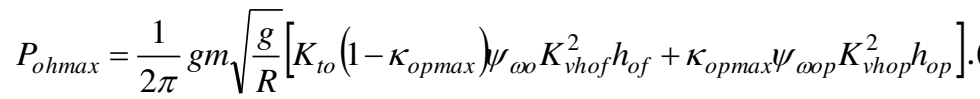

The expression for the ratio of average values for the sum of the vertical components of impact pulses under a self-oscillatory and a steady mode per time unit, taking into consideration (13) and (17), takes the form

$$
\frac{S_{o h}^{u t}}{S_{s h}^{u t}}=\frac{K_{t o}\left(1-\kappa_{o p}\right) \psi_{\omega o} K_{v h o f} \sqrt{h_{o f}}+\kappa_{o p} \psi_{\omega o p} K_{v h o p} \sqrt{h_{o p}}}{K_{t s} \psi_{\omega s} K_{v h s} \sqrt{h_{s f}}} .
$$

Ratio (26) over a period of self-oscillations changes $\left(S_{o h}^{u t} / S_{s h}^{u t}=v a r\right)$, taking into consideration (18) and (19), from a minimum

$$
\left(S_{o h}^{u t} / S_{s h}^{u t}\right)_{\min }=\left(K_{t o} \psi_{\omega o} K_{v h o f} \sqrt{h_{o f} / h_{s f}}\right) /\left(K_{t s} \psi_{\omega s} K_{v h s}\right),
$$

to a maximal value

$$
\left(\frac{S_{o h}^{u t}}{S_{s h}^{u t}}\right)_{\max }=\frac{K_{t o}\left(1-\kappa_{\text {op max }}\right) \psi_{\omega o} K_{v h o f} \sqrt{\frac{h_{o f}}{h_{s f}}}+\kappa_{\text {op max }} \psi_{\omega o p} K_{v h o p} \sqrt{\frac{h_{o p}}{h_{s f}}}}{K_{t s} \psi_{\omega s} K_{v h s}} .
$$

The expression for the ratio of average values for the total power of the vertical components of impact pulses under a self-oscillatory and a steady mode, taking into consideration (21) and (23), takes the form

$$
\frac{P_{o h}}{P_{s h}}=\frac{K_{t o}\left(1-\kappa_{o p}\right) \psi_{\omega o} K_{v h o f}^{2} h_{o f}+\kappa_{o p} \psi_{\omega o p} K_{v h o p}^{2} h_{o p}}{K_{t s} \psi_{\omega s} K_{v h s}^{2} h_{s f}} .
$$

Ratio (29) over a period of self-oscillations changes $\left(P_{o h} / P_{s h}=\right.$ var $)$, taking into account (24) and (25), from a minimum 


$$
\left(P_{o h} / P_{s h}\right)_{\min }=\left(K_{t o} \psi_{\omega o} K_{v h o f}^{2} h_{o f}\right) /\left(K_{t s} \psi_{\omega s} K_{v h s}^{2} h_{s f}\right),
$$

to a maximal value

$$
\left(\frac{P_{o h}}{P_{s h}}\right)_{\max }=\frac{K_{t o}\left(1-\kappa_{\text {op max }}\right) \psi_{\omega o} K_{v h o f}^{2} \frac{h_{o f}}{h_{s f}}+\kappa_{\text {op max }} \psi_{\omega o p} K_{v h o p}^{2} \frac{h_{o p}}{h_{s f}}}{K_{t s} \psi_{\omega s} K_{v h s}^{2}} .
$$

Values of the variables $\kappa_{o p}, K_{t o}, K_{t s}, K_{v h s}, K_{v h o f}, h_{s f}, h_{o f}$ and $h_{o p}$ in expressions (26)-(31) can be determined by visual analysis of the fill motion patterns. Values of variables $\psi_{\omega o}$ and $\psi_{\omega o p}$ can be determined by visual analysis of transient self-oscillating modes of the fill motion. The value of $\psi_{\omega s}$ is specified.

Fig. 7 shows the obtained quasi-static dependences of the $K_{t}$ turnover on the relative rotational velocity $\psi_{\omega}$ for a discrete charge with a relative particle size $d /(2 R)=0.01-0.03$ for the values of the chamber filling degree $\kappa=0.25,0.35$ and 0.45 .

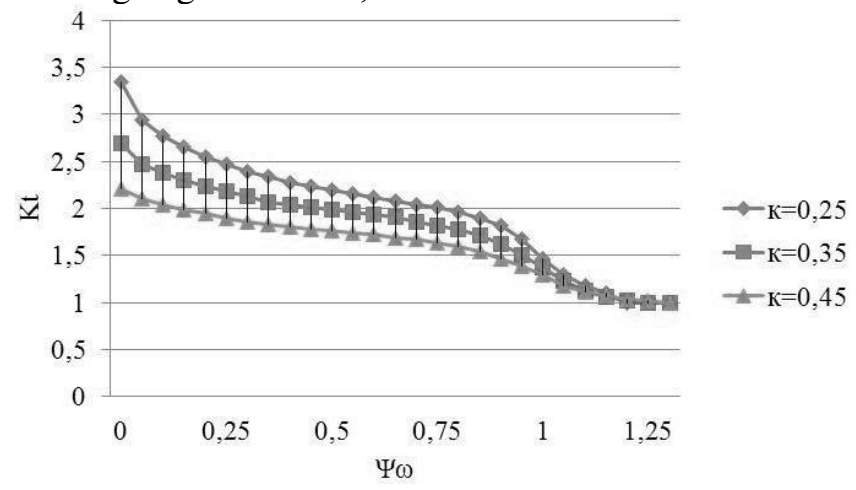

Fig. 7. Dependence of fill turnover $K_{t}$ on relative rotational velocity $\psi_{\omega}$ at $d /(2 R)=0.01-0.03, \kappa=0.25,0.35$ and 0.45

The ratio of the collision parameters for self-oscillating and conventional steady-state operation modes (26) to (31) is convenient to use for comparative assessment of the impact of the grinding fill at different of the chamber filling degrees $\kappa$.

\section{Results obtained in determining the impact action of the fill}

According to the experimental data obtained, geometric and kinematic parameters of the fill motion at the chamber filling degree $\kappa=0.45$ had the following values: $K_{v h s}=0.4, K_{v h o f}=0.75, K_{v h o p}=1$, 
$h_{o f} / h_{s f}=1.54, h_{o p} / h_{s f}=1.46, \psi_{\omega s}=0.75, \psi_{\omega o}=1.1, \psi_{\omega o p}=1.31$ (at $\left.f_{o p} \approx 2 \mathrm{~Hz}\right)$, $K_{t s}=1.63\left(\right.$ at $\left.\psi_{\omega s}=0.75\right), K_{t o}=1.11$ (at $\left.\psi_{\omega o}=1.1\right), \kappa_{\text {opmax }}=0.0662$.

Parameters of the fill motion at the fill $\kappa=0.35$ acquired the following values: $K_{v h s}=0.3, \quad K_{v h o f}=0.75, \quad K_{v h o p}=1, \quad h_{o f} h_{s f}=1.48$, $h_{o p} / h_{s f}=1.6, \psi_{\omega s}=0.75, \psi_{\omega o}=1.075, \psi_{\omega o p}=1.31$ (at $\left.f_{o p} \approx 2 \mathrm{~Hz}\right), K_{t s}=1.82$ (at $\left.\psi_{\omega s}=0.75\right), K_{t o}=1.19$ (at $\left.\psi_{\omega o}=1.075\right), \kappa_{\text {opmax }}=0.12$.

Parameters of the fill motion at the fill $\kappa=0.25$ acquired the following values: $K_{v h s}=0.2, K_{v h o f}=0, K_{v h o p}=1, h_{o f} / h_{s f}=0, h_{o p} / h_{s f}=2.46$, $\psi_{\omega s}=0.75, \psi_{\omega o}=1.05, \psi_{\omega o p}=1.31\left(\right.$ at $\left.f_{o p} \approx 2 \mathrm{~Hz}\right), K_{t s}=2.01$ (at $\left.\psi_{\omega s}=0.75\right)$, $K_{t o}=1.29\left(\right.$ at $\left.\psi_{\omega o}=1.05\right), \kappa_{\text {opmax }}=0.25$.

Relation of average sums of vertical components of the collision momenta and the power of these momenta for self-oscillating and steady-state modes per unit time were determined. According to (27), (28), (30) and (31), extreme values of these relations at the fill $\kappa=0.45$ had the following values: $\left(S_{o h}^{u t} / S_{s h}^{u t}\right)_{\min 0.45}=2.32$,

$$
\begin{aligned}
& \left(S_{o h}^{u t} / S_{s h}^{u t}\right)_{\max 0.45}=2.39, \quad\left(P_{o h} / P_{s h}\right)_{\min 0,45}=5.41, \\
& \left(P_{o h} / P_{s h}\right)_{\max 0,45}=5.7 .
\end{aligned}
$$

Extreme values of parameters of the collision momenta at the fill $\kappa=0.35: \quad\left(S_{o h}^{u t} / S_{s h}^{u t}\right)_{\min 0.35}=2.96, \quad\left(S_{o h}^{u t} / S_{s h}^{u t}\right)_{\max 0.35}=3.07$, $\left(P_{\text {oh }} / P_{\text {sh }}\right)_{\min 0,35}=9.35,\left(P_{o h} / P_{s h}\right)_{\max 0,35}=9.57$.

Extreme values of parameters at the fill $\kappa=0.25$ : $\left(S_{o h}^{u t} / S_{s h}^{u t}\right)_{\min 0.25}=0,\left(S_{o h}^{u t} / S_{s h}^{u t}\right)_{\max 0.25}=5.79, \quad\left(P_{o h} / P_{s h}\right)_{\min 0,25}=0$, $\left(P_{o h} / P_{\text {sh }}\right)_{\max 0,25}=45.5$.

The graphs of dependences $S^{u t} / S_{s h}^{u t}$ for variable values of numerators $S_{s h}^{u t}$ and $S_{o p}^{u t}$ for one period of self-oscillations at the degree of chamber filling with the fill $\kappa=0.25,0.35$ and 0.45 are shown in Fig. 8. 


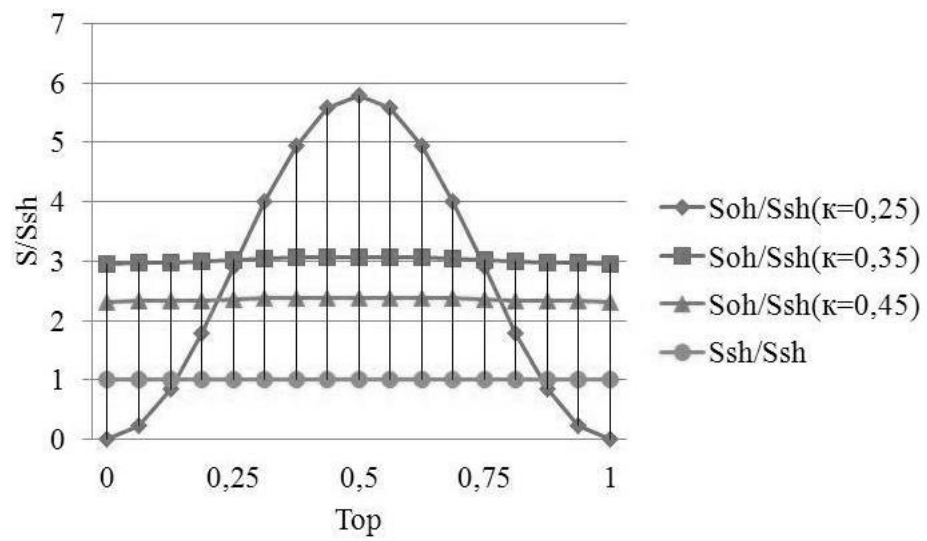

Fig. 8. Dependence of relations of average sums of vertical components of the collision momenta for self-oscillating and steady-state modes per unit time $S_{o h} / S_{\text {sh }}$ and $S_{s h} / S_{s h}$ on the period of self-oscillations $T_{o p}$ at $d /(2 R)=0.01-0.03, \kappa=0.25,0.35$ and 0.45

The graphs of dependences $P / P_{s h}$ for the variable values of numerators $P_{s h}$ and $P_{o h}$ during the self-oscillation period at the chamber filling degree $\kappa=0.25,0.35$ and 0.45 are shown in Fig. 9.

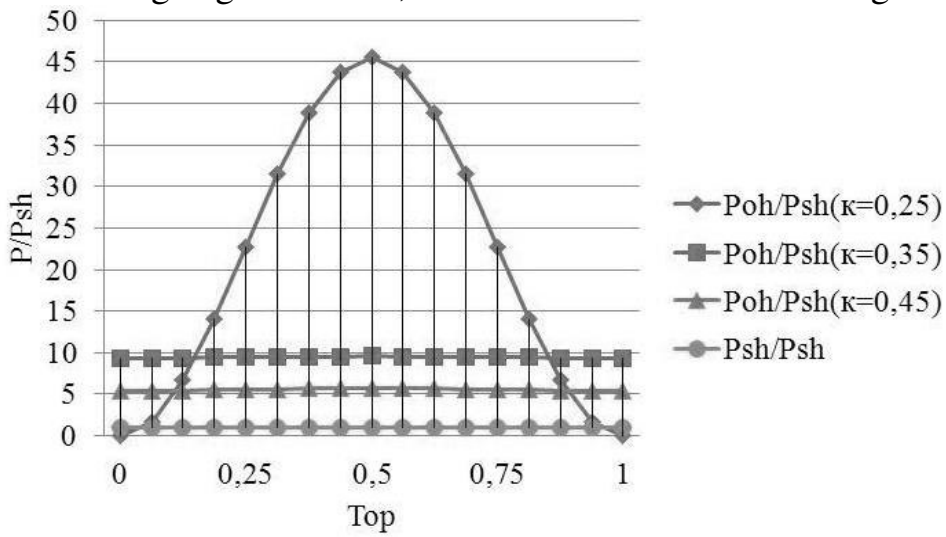

Fig. 9. Dependence of relations of average sums of powers of vertical components of the collision momenta for self-oscillating and steady-state modes per unit time $P_{o h} / P_{s h}$ and $P_{s h} / P_{s h}$ on the period of self-oscillations $T_{o p}$ at $d /(2 R)=0.01-0.03 ; \kappa=0.25$, 0.35 and 0.45

Numerical values of dynamic parameters of the fill impact action indirectly characterize influence of the chamber filling degree $\kappa$ on 
the grinding process course.

\section{Experimental modeling of the grinding process}

Effect of the degree of the chamber filling with the fill on efficiency of the self-oscillating grinding process in a tumbling mill was evaluated for the case of grinding cement clinker.

Particles of pre-crushed clinker with relative size $d_{m} /(2 R)<0.0059$ completely filled in rest condition the gaps between steel ball grinding bodies with relative size $d_{b} /(2 R)=0.026$. Productivity of the grinding process with duration of $30 \mathrm{~min}$ was determined by sieving through a $0.08 \mathrm{~mm}$ mesh sieve.

Technological efficiency of the self-oscillating grinding process was evaluated by relative productivity

$$
\frac{C_{o}}{C_{s}}=\frac{1-m_{r o} / m_{m}}{1-m_{r s} / m_{m}},
$$

where $C_{o}$ is productivity of the self-oscillating process; $C_{s}$ is productivity of the conventional steady-state process; $m_{r o}$ is weight of the sieve residue of the crushed material after sieving during the selfoscillating process; $m_{r s}$ is weight of the sieve residue in the conventional steady-state process; $m_{m}$ is total weight of a portion of ground material prior to sieving.

Power efficiency of the self-oscillating grinding process was evaluated by relative power intensity

$$
\frac{P_{d o}}{P_{d s}}=\frac{\psi_{P 0,5 d}}{\psi_{P 0,5 s}}
$$

and relative specific power intensity

$$
\frac{E_{o}}{E_{s}}=\frac{P_{d o}}{P_{d s}} / \frac{C_{o}}{C_{s}},
$$

where $P_{d o}$ is the power of the drive rotating the filled drum in the selfoscillating process; $P_{d s}$ is the power of the drive in the conventional steady-state process; $E_{o}=P_{d o} / C_{o}$ is the specific power intensity of the self-oscillating process; $E_{s}=P_{d s} / C_{s}$ is the specific power intensity of the conventional steady-state process; $\psi_{P 0,5 o}=\psi_{M 0,5 o} \cdot \psi_{\omega o}$ is the relative power of the drive in the self-oscillating process (Fig. 10); $\psi_{P 0,5 s}=\psi_{M 0,5 s} \cdot \psi_{\omega s}$ is the relative power of the drive in the conventional steady-state process (Fig. 10); $\psi_{M 0,5 o}=M_{0} / M_{\max 0,5}$ is the relative torque of the drive in the self-oscillating process (Fig. 11); $\psi_{M 0,5 s}=M_{S} / M_{\max 0,5}$ 
is the relative torque of the drive in the conventional steady-state process (Fig. 11); $M_{0}$ is the absolute torque of the drive in the selfoscillating process; $M_{s}$ is the absolute torque of the drive in the conventional steady-state process; $M_{\max 0,5}$ is the absolute value of the conditional maximum antitorque for the half-filled chamber $(\kappa=0.5)$ which corresponds to the apparent load distribution over cross section of the drum chamber in a form of an ideal solid-state segment rotated at a right angle relative to the initial position; $\psi_{\omega o}$ is the relative velocity of the drum rotation during the self-oscillating process; $\psi_{\omega s}$ is the relative velocity of the drum rotation in the conventional steadystate process.

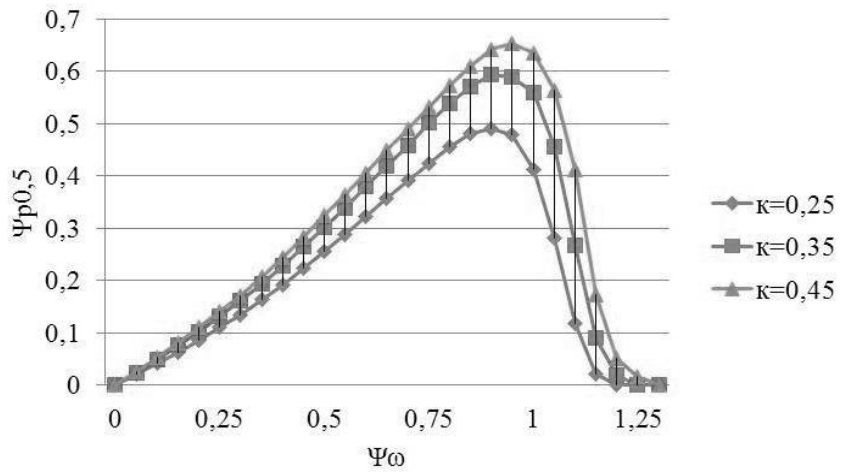

Fig. 10. Dependence of relative power of the drive in rotation of the filled drum, $\psi_{\mathrm{P} 0.5}$, on relative rotational velocity, $\psi_{\omega}$, at $d /(2 R)=0.01-0.03, \kappa=0.25,0.35$ and 0.45

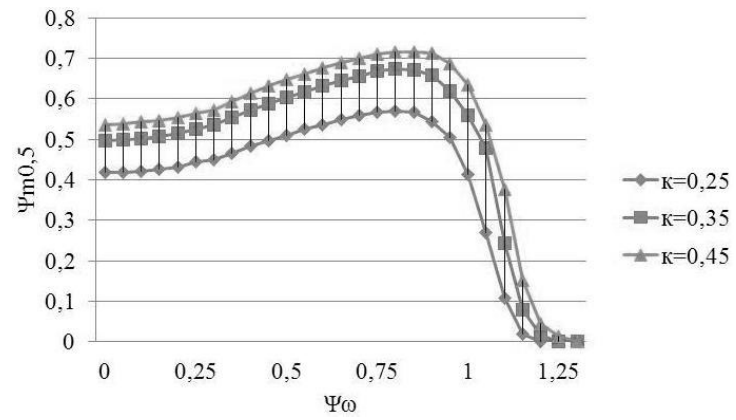

Fig. 11. Dependence of the relative drive torque in rotation of the filled drum, $\psi_{M 0.5}$, on relative velocity of rotation, $\psi_{\omega}$, at $d /(2 R)=0.01-0.03, \kappa=0.25,0.35$ and 0.45

According to the obtained experimental data, technological and power parameters of the process of grinding in a tumbling mill with the chamber 430 
filling degree $\kappa=0.45$ had the following values: $C_{s}=0.435, C_{o}=0.464$, $P_{d s}=0.532$ (at $\left.\psi_{\omega s}=0.75\right), P_{d o}=0.413$ (at $\left.\psi_{\omega o}=1.1\right)$.

Parameters of the grinding process at the chamber filling degree $\kappa=0.35$ acquired the following values: $C_{s}=0.373, C_{o}=0.485$, $P_{d s}=\psi_{P 0,5 s}=0.501$ (at $\left.\psi_{\omega s}=0.75\right), P_{d o}=\psi_{P 0,5 o}=0.375$ (at $\left.\psi_{\omega o}=1.075\right)$.

Parameters of the grinding process at the chamber filling degree $\kappa=0.25$ acquired the following values: $C_{s}=0.323, C_{0}=0.472$, $P_{d s}=\psi_{P 0.5 s}=0.424$ (at $\left.\psi_{\omega s}=0.75\right), P_{d o}=\psi_{P 0.5 o}=0.282\left(\right.$ at $\left.\psi_{\omega o}=1.05\right)$.

Then, according to (32) and (34), relative productivity, power intensity and specific power intensity of the self-oscillating grinding process at the chamber filling degree $\kappa=0.45$ have the following values: $C_{0} / C_{s}=1.067, P_{d o} / P_{d s}=0.776, E_{o} / E_{s}=0.728$.

Relative characteristics of the self-oscillatory process at the chamber filling degree $\kappa=0,35$ acquired the following values: $C_{0} / C_{s}=1.3, P_{d o} / P_{d s}=0.749, E_{0} / E_{s}=0.576$.

Relative characteristics of the self-oscillatory process at the chamber filling degree $\kappa=0,25$ acquired the following values: $C_{0} / C_{s}=1.46, P_{d o} / P_{d s}=0.665, E_{o} / E_{s}=0.455$.

Graphs of the obtained dependences of $C_{o} / C_{s}, P_{d o} / P_{d s}$ and $E_{o} / E_{s}$ on the chamber filling degree $\kappa$ are shown in Fig. 12.

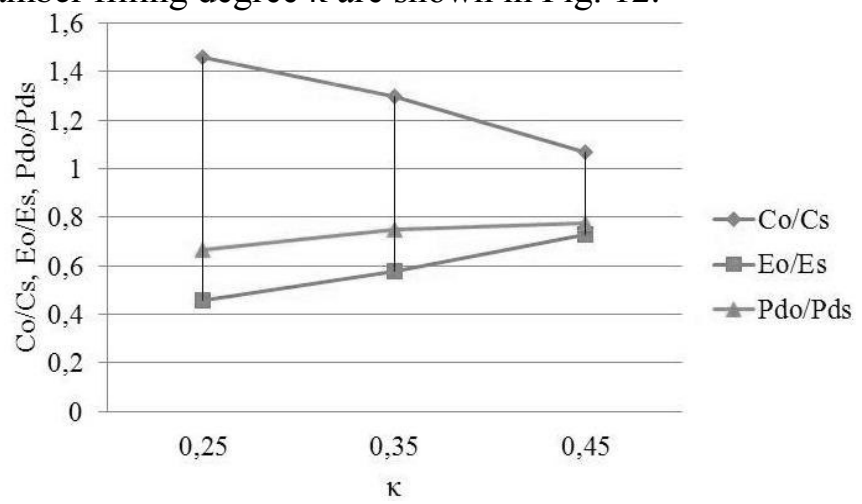

Fig. 12. Dependences of $C_{0} / C_{s}, E_{o} / E_{s}$ and $P_{d o} / P_{d s}$ of the self-oscillating process of grinding cement clinker at $d_{b} /(2 R)=0.026$ and $d_{m} /(2 R)<0.0059$ on $\kappa$

Dependences of relative productivity, power intensity and specific power intensity characterize influence of the chamber filling degree on efficiency of the self-oscillating process of grinding. 


\section{Conclusions}

1. Ratio of the average sums of the vertical components of the collision momenta per unit time for self-oscillating and steady-state motion modes was approximately determined numerically. For the relative size of the ball elements of the fill of $0.01-0.03$, this ratio was approximately 2.32-2.39 at the chamber filling degree $\kappa=0.45,2.96$ 3.07 at $\kappa=0.35$ and $0-5.79$ at $\kappa=0.25$. Ratio of the average sums of powers of such impacts per unit of time under such conditions was 5.41-5.7 at $\kappa=0.45,9.35-9.57$ at $\kappa=0.35$ and $0-45.5$ at $\kappa=0.25$.

2 . With a decrease in a chamber fill, $\kappa$, the self-oscillating impact action increases significantly due to the decrease in the passive quasisolid zone and a significant increase in the active pulsation zone of the fill motion in cross section of the rotating chamber. This is due to manifestation of the dynamic effect of significant increase in the selfoscillations swing with a decrease in $\kappa$.

3. A decrease in relative specific power intensity in grinding cement clinker was established experimentally for an innovative selfoscillating process compared to the conventional process. For the relative size of the fill particles of 0.026 and complete filling of the gaps between the grinding bodies, this reduction was approximately $27.2 \%$ at $\kappa=0.45,42.4 \%$ at $\kappa=0.35$ and $54.5 \%$ at $\kappa=0.25$. Under these conditions, relative productivity of the self-oscillating process has increased by about $6.7 \%$ at $\kappa=0.45$, by $30 \%$ at $\kappa=0.35$ and by $46 \%$ at $\kappa=0.25$.

4. It was established that with a decrease in the chamber fill, $\kappa$, specific power intensity and productivity of the self-oscillating grinding process carried out in the tumbling mill significantly decrease. This is due to manifestation of the technological effect of a significant increase in the impact action of the grinding bodies on particles of the crushed material and some decrease in the drive power spent for rotation of the filled drum with a decrease in $\kappa$. 


\section{References}

1. Deineka, K., \& Naumenko, Y. (2019). Revealing the effect of decreased energy intensity of grinding in a tumbling mill during self-excitation of auto-oscillating of the intrachamber fill. Eastern-European Journal of Enterprise Technologies, 1, 1 (97), 6-15. doi.org/10.15587/1729-4061.2019.155461

2. Deineka, K., \& Naumenko, Y. (2019). Establishing the effect of a decrease in power intensity of self-oscillation grinding in a tumbling mill with decrease of intrachamber fill. Eastern-European Journal of Enterprise Technologies, 6 (7(102)), 4352. doi.org/10.15587/1729-4061.2019.183291

3. Deineka, K. Y., \& Naumenko, Y. V. (2018). The tumbling mill rotation stability. Naukovyi Visnyk Nationalnoho Hirnychoho Universytetu - Scientific Bulletin of National Mining University, 1 (163), 60-68. doi.org/10.29202/nvngu/2018-1/10

4. Deineka, K. Y., \& Naumenko, Y. V. (2016). Parametry avtokolyvan vnutrishnokamernoho zavantazhennia barabannoho mlyna [Self-oscillation parameters of tumbling mill intrachamber fill]. Vibratsii v tekhnitsi ta tekhnolohiiakh - Vibration in Technics and Technologies, 3 (83), 29-34 [in Ukrainian].

5. Naumenko, Y. V., \& Deineka, K. Y. (2017). Vplyv stupenia zapovnennia obertovoi kamery na avtokolyvannia zernystoho zavantazhennia [The influence of the degree of filling of the rotating chamber on the self-oscillating grain fill]. Vibratsii $v$ tekhnitsi ta tekhnolohiiakh - Vibration in Technics and Technologies, 4 (87), 65-69 [in Ukrainian].

6. Deineka, K. Y., \& Naumenko, Y. V. (2018). Vplyv struktury polidyspersnoho zavantazhennia obertovoho barabana na samozbudzhennia avtokolyvan [Influence of structure of polydisperse fill of rotating drum on self-excited self-oscillations]. Vibratsii v tekhnitsi ta tekhnolohiiakh - Vibration in Technics and Technologies, 3 (90), 75-82 [in Ukrainian].

7. Deineka, K. Y., \& Naumenko, Y. V. (2019). Vplyv dribnoi fraktsii polizernystoho zavantazhennia obertovoho barabana na rozmakh avtokolyvan [Influence of small fraction of polygranular fill of rotating drum on self-oscillation swing]. $\mathrm{Vi}$ bratsii $v$ tekhnitsi ta tekhnolohiiakh - Vibration in Technics and Technologies, 4 (95), 31-37 [in Ukrainian]. doi:10.37128/2306-8744-2019-4-4 